\title{
DAS POSSIBILIDADES DE UM CONCEITO DE SAÚDE
}

\section{ON THE POSSIBILITIES FOR A NEW CONCEPT OF HEALTH}

\author{
Marcelo José de Souza e Silva (iD) ${ }_{(0000-0002-4862-9460)}{ }^{1}$, Lilia Blima Schraiber ID $_{(0000-0002-3326-0824)^{2}}$ \\ André Mota ${ }^{2}$ (D) \\ ${ }^{1}$ Universidade Federal do Paraná, Departamento de Saúde Coletiva, Curitiba, Paraná, Brasil. \\ $<$ marcelojss@gmail.com> \\ ${ }^{2}$ Universidade de São Paulo, Faculdade de Medicina, Departamento de Medicina Preventiva, São Paulo, \\ São Paulo, Brasil.
}

Resumo O estudo tem como objetivo discutir o que é um conceito a partir da adoção do referencial teórico marxista para defini-lo, com o intuito de responder se é possível ou não existir um conceito de saúde. Foi realizada leitura de autores marxistas que tratam da relação entre pensamento e a realidade objetiva, buscando se apoiar em variados autores dentro deste referencial, para enriquecer o debate contemporâneo na Saúde Coletiva. Como resultado, entendemos que o conceito é a forma de apreensão pelo pensamento dos objetos presentes na realidade objetiva e que, exatamente por não conter as características concreto-fatuais presentes em cada caso particular, permite entendê-los com base em sua essência como objeto abstrato-universal. Dessa forma, concluímos que, apesar de a saúde ser um objeto extremamente complexo, é possível existir seu conceito, o qual, segundo nossos referenciais, deve remeter ao todo sócio-histórico e à politização da dimensão técnica que esteja implicada historicamente com este social.

Palavras-chave saúde coletiva; formação de conceito; saúde; trabalho; conhecimento.
Abstract The study has the goal of discussing what is a concept based on the adoption of the Marxist theoretical framework to define it, with the intent of answering whether the existence of a concept of health is possible or not. We read Marxist authors who deal with the relationship between thought and objective reality, trying to rely on many different authors within this framework, in order to enrichen the current debate in Collective Health. As a result, we understand that that the concept is the way in which thought apprehends the objects that are present in objective reality and that, precisely because it does not contain the concrete-factual features that are present in each particular case, it enables us to understand them based on their abstract-universal objects. Therefore, we conclude that, even though health is an extremely complex object, the existence of its concept is possible, and, according to our frameworks, this concept must refer to the socio-historic whole and to the politicization of the technical dimension that is historically implicated with this social.

Keywords collective health; formation of concepts; health; labor; knowledge. 


\section{Introdução}

Buscamos, no presente estudo, discutir a possibilidade ou não da existência de um conceito de saúde, com base em elaborações de autores que se vinculam ao marxismo como referencial teórico, sobre o que é propriamente um 'conceito', sem nos preocuparmos, neste momento, em conceituar definitivamente o que é saúde, tomando-o como uma existência concreta que pode ou não ser conhecida objetivamente. Essa questão surge como parte de uma pesquisa mais ampla para entender como tem sido tratado esse conceito dentro do movimento chamado Saúde Coletiva, por ser o espaço que entrelaça questões teóricas com questões práticas e que pretende superar criticamente a redução da saúde como não doença, do ponto de vista biomédico, tal como é concebida pela prática até então. Dessa forma, é de interesse saber como os autores que se vinculam a esse movimento vêm pensando o que é a própria saúde e identificar em autores do referencial teórico marxista, ainda pouco conhecidos na Saúde Coletiva, novas contribuições, em diálogo com o pensamento social em saúde e objetivando enriquecer o debate na área.

Segundo Silva (2017), podemos encontrar, entre as publicações concernentes à Saúde Coletiva, levantadas com base em periódicos dessa área como área de conhecimento da Coordenação de Aperfeiçoamento de Pessoal de Nível Superior (Capes), três tipos de trabalhos que abordam de alguma forma o conceito de saúde: aqueles nos quais ele estava ainda em construção; aqueles que trataram saúde como um lema político, mas não a conceituaram; e até os que tendem a concluir a impossibilidade de existência de um conceito de saúde. Essa classificação tem por base referentes para definir o que é um conceito que são diversos dos usados nessas publicações, como iremos considerar.

Chama-nos a atenção especialmente os dois últimos grupos, pois os que trataram saúde como um lema político muitas vezes aderiram de forma a priori às definições de documentos oficiais, como, por exemplo, os da Organização Mundial da Saúde, sem apresentar razões para tal escolha. Enquanto que as publicações em que é negada a possibilidade de conceituar saúde constituíram uma dissociação entre a realidade empírica, que é explorada e considerada reflexivamente, e a impossibilidade de nomeá-las, dando-lhes conteúdos significativos nessa mesma reflexão, mas desvinculados da realidade empírica analisada. Tal situação extrema merece ser repensada, pois entendemos ser relevante debater a possibilidade ou não de existir um conceito de saúde.

Czeresnia (1999, p. 702, tradução nossa), diz que “a palavra, embora uma forma elaborada de expressão e comunicação, é insuficiente para apreender a realidade em sua totalidade". De acordo com a autora (1999, p. 703, tradução nossa), "saúde e adoecimento são formas pelas quais a vida se manifesta. São experiências únicas, subjetivas; palavras não podem reconhecer e significa-las completamente", pois "saúde não é um objeto que pode ser restringido dentro do campo do conhecimento objetivo. A saúde não se 
traduz em um conceito científico". De fato, ao complementar esse estudo, Czeresnia et al. (2013, p. 14-15) também argumentam que o conceito "expressa as identidades e não as diferenças entre os fenômenos que explica", buscando representar a realidade em detrimento das singularidades dos diversos casos, constituindo-se como ente abstrato que foge à realidade por não conseguir expressar também o diverso. Outro estudo identificado com essa posição foi o de Costa e Bernardes (2012), que argumentam, com base na hermenêutica, que a saúde, entendida como ontologia mínima, pode ser nomeada, mas não conceituada, pois a Saúde seria um nome próprio, da ordem do 'é' e não do 'que é', o que faz com que a produção de saúde se torne produção de vida e produção de subjetividades.

Essa perspectiva da impossibilidade de existir um conceito de saúde extrapola a própria Saúde Coletiva, com outros autores que também fazem análises com essa premissa: Dalmolin et al. (2011, p. 390) dizem que “a saúde, diferentemente do que muitos pensam, acreditam ou defendem, não pode ser apreendida como um fenômeno abstrato e nem mesmo como algo concreto ou atingível"; Boruchovitch e Mednick (2002, p. 177, tradução nossa), afirmam que "um conceito adequado e válido universalmente de saúde é irrealizável porque a saúde é um termo carregado de valor, cujo significado está altamente ligado a diferentes objetivos que governam seu uso".

Para estes autores o conceito englobaria somente aquilo que é comum, entretanto, como a realidade é necessariamente composta por diferentes, o conceito não representaria de fato a realidade. Parece-nos que estes autores tomam o abstrato como sinônimo de forma pura de pensamento, em oposição à realidade objetiva (o concreto), o que faz com que o concreto e o abstrato estejam em oposição excludente um em relação ao outro. Dessa forma, a transposição do concreto para o abstrato 'destruiria' as propriedades percebidas sensorialmente do concreto.

É, portanto, de interesse da própria Saúde Coletiva debater se é realmente possível conceituar saúde, já que para alcançar o objetivo de entrelaçar a teoria com a prática é necessário que os objetos existentes no mundo real sejam passíveis de serem apreendidos pelo pensamento na forma de conhecimento. E, apesar de termos neste momento como foco o objeto saúde, essa questão extrapola para todas as temáticas recortadas pela produção de conhecimento, pois a saúde não é o único objeto diverso existente na realidade objetiva. Portanto, argumentar que não é possível conceituar um objeto cuja expressão concreto-factual abre um leque de diversidades pode apontar a impossibilidade de um conhecimento objetivo sobre qualquer realidade.

Dessa forma, recuperamos diversos autores marxistas que tratam da questão da formação do conceito no pensamento e de sua relação com a realidade objetiva, tanto aqueles já consagrados quanto aqueles menos conhecidos dentro da Saúde Coletiva, para com isso enriquecer o debate. Com base na 
elaboração desses autores, buscaremos responder se é possível ou não existir um conceito de saúde.

Partiremos, assim, de referenciais que definem o conceito como um concreto pensado, e, ainda que não apreenda tudo, aproxima-se de totalidades sociais que delimita e pode valorizar o diverso da realidade empírica dentro do pensamento. E, entendemos esse pensamento como o movimento reflexivo que toma o concreto particular (o empírico em questão e estudado para ser alvo da compreensão teórico-conceitual), e em sua própria elaboração realiza as conexões entre o particular e o todo social de que faz parte, para assim formular o conceito sobre o objeto em estudo. A seguir passamos a detalhar essa concepção e o caminho de sua elaboração. Assim, discutiremos aqui o que é um conceito mediante esse referencial teórico, para que, ao final, possamos ter subsídios para o percurso do pensamento nessa formulação, indicando-se um caminho potencialmente produtivo para, em um momento subsequente, buscarmos o conceito de saúde.

\section{O conceito no senso comum}

Segundo Blunden (2012), no senso comum, o conceito é identificado com um nome (palavra) ou até mesmo com um conjunto de atributos que caracterizam alguma coisa. No meio acadêmico, temos visto o conceito ser identificado como 'algo abstrato', com o sentido de estar deslocado da realidade e, portanto, considerado como algo que não engloba exatamente esse conjunto de atributos que caracterizam alguma coisa.

Um autor pouco conhecido na Saúde Coletiva e que foi largamente adotado em nossa pesquisa, por trazer contribuições importantes nesse sentido, foi Evald Ilienkov, um filósofo soviético que teve como cerne de sua obra o confronto ao neopositivismo/empirismo, "a partir de uma abordagem dialética entre o abstrato e o concreto, entre o real e o ideal, como forma de entendimento verdadeiro sobre a realidade da atividade prática social humana e sua manifestação dialética e mediada na consciência humana" (Silva, 2016, p. 108).

Segundo Ilyenkov (2008, p. 39, tradução nossa):

O conceito foi definido como designação verbal do geral em um número de ideias simples (noções), como um nome/termo (Locke, Hobbes), ou simplesmente como "qualquer noção da coisa em nosso pensamento" (Christian Wolff), ou como "algo oposto à contemplação, na medida em que é uma noção geral ou uma noção de o que é mais comum a muitos objetos da contemplação" (Kant), ou como "noção do definitivo, inequívoco, estável, significado usualmente aceito" (Sigwart), ou como "noção da noção" (Schopenhauer). Hoje em dia, também, amplamente atual é a definição de conceito como simplesmente "o significado semântico de um termo", o que quer que seja que isso signifique. 
Entretanto, não entendemos conceito como uma palavra que encerra em si o comum a muitos casos, pois, ao identificar o conceito com o conjunto de características compartilhadas por determinado grupo de objetos ou fenômenos, nós podemos somente descrevê-los. Também não identificamos o conceito como 'algo tão abstrato' que não aponte suas conexões com a realidade concreta e particular a que nomeia e através do qual não é possível representar a realidade por estar deslocado desta.

Ilienkov (2016b) usa a história de Vercors em seu livro Les Animaux Dénaturés para demarcar essa diferença. O objetivo do autor, ao examinar esse romance, é explicar que o universal - o conceito - não pode ser entendido como uma abstração formal que revele as características comuns de diversos objetos particulares, que revele o idêntico neles.

A obra conta a história da busca pelo elo perdido, a chave que explicaria a evolução do macaco ao ser humano; nessa busca é encontrado, em uma floresta tropical, um grupo de criaturas estranhas que passaram a ser chamadas de Tropi. De acordo com a antropologia moderna, as criaturas seriam macacos ou seres humanos primitivos. A questão que surge na história é: será que os Tropi cruzaram a linha tênue e extremamente importante entre animal e ser humano?

Para que não se restringisse a um problema meramente acadêmico, a personagem principal do romance engravida uma das criaturas e na continuação mata deliberadamente seu filho recém-nascido. É preciso agora decidir se foi cometido um assassinato ou não. O padre do local também se vê no mesmo problema, pois se os Tropi são seres humanos, é preciso salvar suas almas e batizá-los; se não forem, não pode cometer o mesmo erro de São Mahel, que batizou pinguins, causando uma confusão no céu. E para os capitalistas, se as criaturas não forem seres humanos, serão a força de trabalho ideal, por ser um animal fácil de domesticar e incapaz de tomar consciência da luta de classes.

Muito se discute sobre a questão, mas é preciso uma resposta categórica e inequívoca para resolver os diversos impasses. Quando as personagens dão ênfase em uma determinada característica 'humana', os Tropi entram na categoria seres humanos; quando dão ênfase em outra, não entram. A soma de características não é de muita ajuda, pois recai na questão de qual o número suficiente; dependendo das características escolhidas, os Tropi entram novamente na categoria seres humanos; se é introduzida uma característica que os Tropi não possuem, são excluídos da categoria. Dessa forma, não se consegue decidir se os Tropi são seres humanos sem antes saber o que caracteriza um ser humano; entretanto, não se pode definir o que é um ser humano sem antes saber se os Tropi o são ou não, para saber se suas características serão consideradas.

Disso decorre outro problema: o que são as características elencadas? O que é linguagem, pensamento etc.? Dependendo da definição das caracterís- 
ticas, outros animais, que não só o ser humano, também a possuirão. Esses animais deverão ser incluídos na categoria seres humanos? E todos os seres humanos possuem as mesmas características, sendo possível elencar aquelas que definem o que é um ser humano? Além disso, todos agem de ‘forma humana'? Isso leva a mais um problema: qual o tipo de vida genuinamente humano? Existe esse tipo de vida?

Segundo Ilienkov (2016b), caímos em um problema antigo: só é possível abstrair uma característica comum de todos os sujeitos se e quando o conjunto que os constitui enquanto gênero é bem definido. Entretanto, isso só é possível se existir um critério geral a priori para identificar esse conjunto, ou seja, a própria característica comum procurada. Ao perceberem que traçar a característica essencial e comum do ser humano, ou seja, o que define concretamente um humano não é tarefa fácil, as personagens se voltam para concepções filosóficas e sociológicas. Entretanto, chegam a outro dilema: qual é o critério da verdade dessas concepções? Cada uma reivindicou para si importância universal, e excluiu as outras concepções, não existindo, portanto, qualquer acordo entre elas. Qual delas, portanto, possui a capacidade de decidir o que é um ser humano?

O romance termina com a personagem principal precisando de escolher entre o universal marxista e o universal cristão de ser humano; ela busca então uma terceira alternativa, o comum entre essas duas concepções, que seria a definição genuína de ser humano. “'Cada homem é, primeiro de tudo, humano, um ser humano, e somente depois disso, um seguidor de Platão, Cristo ou Marx', argumenta Vercors no posfácio da edição russa do romance" (Ilienkov, 2016b, p. 94). Entretanto, essa resposta leva ao problema do início do romance, ao início do debate sobre qual é a essência de ser humano, pois nada além de uma tautologia pode resultar da tentativa infrutífera de abstrair o universal de ser humano com base nas características comuns das pessoas concretas.

Essa forma - essa lógica - de tentar resolver a questão não permite retirar o pensamento de um impasse e deixa a questão principal, o que é um ser humano, sem ser realmente pensada e respondida.

Dessa forma, para nós o conceito - o universal - não é um conjunto de atributos que caracterizam alguma coisa, as características concreto-fatuais (ou seja, existem, mas são casuais) comuns a todos os sujeitos e objetos de um determinado grupo ou conjunto ou ainda de um 'algo abstrato' entendido em oposição e fora da realidade material e objetiva. Segundo Vigotski (2009), os conceitos não se encontram no discurso cotidiano; nele, os termos usados, mesmo que inspirados ou próximos dos conceitos, são noções gerais sobre as coisas, um estado transitório entre o pensamento por complexos e pseudoconceitos e os verdadeiros conceitos. Ilyenkov (2008) complementa que não se pode reduzir o conceito, como fazem os 
neopositivistas, a uma questão de estabelecer o significado de um termo em um sistema de termos construído de acordo com regras formais. Por isso, de acordo com Lukács (2013), é preciso primeiro realizar a decomposição do objeto e/ou sujeito, pela via analítico-abstrata, para se chegar ao seu fundamento; e com base nesse fundamento, retornar ao complexo do ser social, ao complexo de características concreto-fatuais, compreendido agora em sua totalidade como humano-social. Também Lefebvre (1983) dirá que da percepção de um problema à construção de um conceito que, no interior de determinada teoria, articule o problema particular-concreto a uma totalidade social explicativa, é necessário um movimento entre o vivido e o pensado, concluindo ser o conceito o 'concreto pensado' na totalidade social que o produz (e que ele reproduz) e o explica para nós.

\section{0 trabalho como atividade teleológica do ser humano}

Para entendermos o que é um conceito, é mister compreender a relação entre o material e o pensamento, a realidade objetiva e a consciência, que é específica do ser humano. Para isso, é se faz necessário apreender como surge a própria consciência do ser humano.

Todos os animais realizam certa atividade, entretanto, apenas o ser humano a realiza voltada para um fim (teleológica), ou seja, ela é intencional, pois o ser humano pensa no seu objetivo antes mesmo de realiza-la; está na mente do trabalhador antes da própria ação de transformação; ela possui um momento subjetivo que se exterioriza na realidade objetiva e que cada vez mais se distancia da atividade animal baseada somente no instinto. Essa atividade teleológica é o que chamamos de trabalho - entendido aqui de forma geral, como obra humana, e não da forma como se expressa no modo de produção capitalista, como trabalho alienado, em que para o ser humano o seu produto não mais é concebido como obra sua. Aproveitamos para deixar claro, nas palavras de Lukács (2012, p. 340), que apenas a atividade transformadora do mundo é teleológica, pois "nossas análises rejeitam toda forma generalizada de teleologia, não apenas na natureza inorgânica e orgânica, mas também na sociedade, restringindo sua validade nos atos singulares do meio humanosocial, cuja forma mais explícita e cujo modelo é o trabalho" e que não consideramos que a história seja teleológica, como em Hegel. Vázquez (2011, p. 225) complementa ainda que essa atividade teleológica também permite que, com base em uma realidade conhecida, o ser humano possa "prever uma fase de seu desenvolvimento que ainda não ocorre. Tal é a legítima função da previsão científica. Com ela, antecipa-se idealmente o que ainda não existe efetivamente".

O trabalho é uma atividade de transformação da natureza, que surge da fragilidade do Homo sapiens em relação a ela, pois, diferente dos outros 
animais, são seres cuja constituição biológica é muito mais frágil em relação ao restante da natureza. Dessa fragilidade surge a necessidade de sobreviver dependendo de outros seres iguais, outros Homo sapiens, assim como de modificar o que a natureza fornece, produzindo meios (instrumentos) que lhes permitam realizar essa transformação.

O ser humano transforma a natureza, o potencial latente existente nela, com o intuito de se apropriar dela e sanar suas necessidades (tanto biológicas, quanto culturais) e, nesse movimento de transformação da natureza externa, transforma sua própria natureza interna, a si mesmo como ser humano. Transforma-se a natureza, em primeiro lugar, para garantir a própria condição de vida, pois "para viver, precisa-se, antes de tudo, de comida, bebida, moradia, vestimenta e algumas coisas mais" (Marx e Engels, 2009, p. 33). Mas isso não está dado naturalmente, é preciso criar esses meios de vida. Essa produção leva a novas necessidades, através de uma relação dupla - tanto natural quanto social.

Pode-se distinguir os homens dos animais pela consciência, pela religião ou pelo que se queira. Mas eles mesmos começam a se distinguir dos animais tão logo começam a produzir seus meios de vida, passo que é condicionado por sua organização corporal. Ao produzir seus meios de vida, os homens produzem, indiretamente, sua própria vida material (Marx e Engels, 2009, p. 87).

Partimos do próprio ser humano, entretanto, não de forma isolada ou fantástica, mas como ser social, "em seu processo de desenvolvimento real, empiricamente observável, sob determinadas condições" (Marx e Engels, 2009, p. 94). Fazemos isso, pois a forma como o ser humano produz sua vida em sociedade depende, primeiramente, de como ele encontra os meios de vida, que ele precisa reproduzir e desenvolver - dado que essa reprodução não está reduzida apenas à existência física dos indivíduos, mas também à sua existência cultural (entendida de forma ampla). O modo de produção, ou seja, a forma como se organiza a produção da vida em determinado momento histórico, é a forma de exteriorizar sua vida, de se objetivar, de criar uma realidade objetiva, que se torna o modo de vida dos indivíduos. E a forma como esses indivíduos exteriorizam suas vidas é a forma como são eles próprios, pois eles coincidem com sua produção, "tanto com o que produzem como também com o modo como produzem. O que os indivíduos são, portanto, depende das condições materiais de sua produção" (Marx e Engels, 2009, p. 87, grifos no original).

Segundo Marx (2013), o trabalho é, primeiramente, um processo entre o ser humano e a natureza, um processo de transformação da natureza pela ação do próprio ser humano, que media, controla e regula seu metabolismo com a natureza. Ele aparece primeiramente como um meio para satisfazer a necessidade de manutenção da existência física, pois, não importa a forma 
como os produtos do trabalho apareçam após diversas transformações, o ser humano vive fisicamente somente dos produtos da natureza. Entretanto, o Homo sapiens não consegue individualmente realizar essa transformação, pois ele é subjugado por essa natureza; é preciso transformá-la em conjunto com outros sujeitos. Desde esse momento, o Homo sapiens deixa de ser apenas mais uma espécie animal e se torna ser humano, pois começa a universalizar a natureza. Essa universalização ocorre, pois o ser humano, ao mesmo tempo em que continua a ser dependente da natureza, passa também a ser independente dela - ao mesmo tempo em que extrai dela os produtos necessários para sua sobrevivência, a transforma para atender as necessidades humanas. Já os outros animais têm uma relação parcial (limitada) com a natureza, que os impede de se tornarem seres universais, pois vivem de acordo com o que a natureza lhes fornece, se constituindo, então, como a própria natureza. Disso segue que a vida produtiva do ser humano se torna sua vida genérica, pois faz de sua totalidade como ser seu corpo inorgânico - que se constitui os instrumentos, tanto técnicos quanto psíquicos, que estendem o seu potencial biológico, orgânico -, porque se trata de um meio de vida imediato e de objeto, matéria, e instrumento de sua atividade vital, além de permitir que se diferencie da atividade animal, baseada somente no instinto.

Ao transformar a natureza, o ser humano se apropria dela e a incorpora à prática social, à prática de produção da vida em conjunto com outros seres humanos. Desse momento em diante, o que constitui o ser humano não é mais apenas seu lado natural, biológico, mas também seu lado não natural, que são as formas socioculturais e os produtos do trabalho humano em geral. Nesse movimento de transformação da natureza, o ser humano, ao mesmo tempo, também se objetiva, produz uma realidade objetiva com características humanas - pois adquire características socioculturais - desenvolvidas e acumuladas por diversas gerações de seres humanos (Duarte, 2008).

Assim, é somente o trabalho que possui a característica que permite a inter-relação entre o ser humano (a sociedade) e a natureza, tanto inorgânica (ferramentas, objetos do trabalho, entre outros) como orgânica, assinalando assim a transição do ser meramente biológico ao ser social (Lukács, 2013).

É apoiado no trabalho que o ser humano transforma tanto o mundo - a realidade objetiva - quanto o próprio ser que trabalha, inclusive seu pensamento sobre esse mundo. Como a transformação da natureza, que gera uma transformação no próprio ser que trabalha, só se realiza em conjunto com outros seres humanos, faz-se necessário tanto o pensamento sobre qual o objetivo da atividade quanto a exteriorização desse pensamento em forma de comunicação, criando assim instrumentos psíquicos como meios para realizar essa atividade. Além disso, segundo Vigotski (2009), tais instrumentos terão a palavra como célula principal e o conceito como sua forma superior. Assim, da mesma forma como produz sua vida, o ser humano também produz suas 
representações, suas ideias em relação ao mundo ao seu redor. Entretanto, produz ideias que não estão deslocadas desse mesmo mundo objetivo, mas que são determinadas por ele, principalmente pelo desenvolvimento das forças produtivas e pelas relações de produção (as forças e relações para a produção da vida) em determinado momento histórico, pois são dessas relações, dessa produção da vida em sociedade, que se constitui o ser social, que é um ser consciente.

A consciência é, portanto, o próprio ser consciente. Este ser, no humano, é o seu processo de vida real, pois, ao desenvolver a forma como produz sua vida, a humanidade transforma a própria realidade e, mediante essa nova realidade, seu próprio pensar e os produtos do seu pensar (Marx e Engels, 2009).

Segundo Marx (2009), com base na transformação das forças produtivas, a humanidade engendra o seu modo de produção; e ao fazê-lo, cria também as relações sociais e produz, "também, os princípios, as ideias, as categorias de acordo com as suas relações sociais" (Marx, 2009, p. 126), pois o ser humano é condicionado pelo modo de produção de sua vida material, por um determinado desenvolvimento das forças produtivas, assim como o intercâmbio que a elas corresponde (Marx e Engels, 2009).

Assim, para o humano, é possível ser um ser consciente e, além disso, é possível a exteriorização de seu subjetivo para a realidade objetiva através do trabalho. Entretanto, isso não ocorre imediatamente, pois, segundo Mamardašvili (1986), entre o objeto e a subjetividade humana, existe todo um sistema de elos sociais com significado - os elos do intercâmbio de atividades entre as pessoas, pois os códigos da consciência são representações de objetos que foram engendrados por mecanismos sociais. Portanto, a consciência é julgada de acordo com transformações específicas a que as relações reais estão sujeitas. “O texto é escrito pela sociedade, mas está codificado nos indivíduos" (Mamardašvili, 1986, p. 111, tradução nossa).

E essa relação entre objeto e sujeito mediada pelo trabalho (que possui uma finalidade) torna possível o dinamismo das sociedades humanas e, consequentemente, sua história - de superações e retrocessos -, não sendo possível analisá-las com base em leis mecânicas, o que faz com que, de acordo com Maher (2016, p. 305, tradução nossa), "somente em referência ao processo real da história concreta que se pode avaliar a significância de qualquer evento específico naquele processo". Dessa forma, "nem os pensamentos nem a linguagem constituem um reino próprio; eles são apenas manifestações da vida real" (Marx e Engels, 2009, p. 429, grifos no original). Portanto, "não é a consciência dos homens que determina o seu ser; ao contrário, é o seu ser social que determina sua consciência" (Marx, 2008, p. 47).

A forma de exteriorização da consciência é a linguagem, que "é a consciência real, prática, que existe para os outros homens e que, portanto, também existe para mim mesmo" (Marx e Engels, 2009, p. 34), e ambas nascem da 
necessidade de intercâmbio entre os seres humanos. Dessa forma, a consciência sempre foi um produto social, que no início era apenas a consciência do meio sensorial mais imediato, assim como do vínculo limitado, tanto com outras coisas quanto com coisas exteriores ao indivíduo que se torna consciente. Ou seja, é consciência, ao mesmo tempo, da natureza (que se apresenta inicialmente como "um poder totalmente estranho, onipotente e inabalável, com o qual os homens se relacionam de um modo puramente animal" (Marx e Engels, 2009, p. 35) e "da necessidade de firmar relações com os indivíduos que o cercam constitui o começo da consciência de que o homem definitivamente vive numa sociedade" (Marx e Engels, 2009, p. 35).

Assim, compreendemos que pelo trabalho o ser humano transforma o mundo e a si mesmo como ser, assim como a sua consciência sobre esse mundo, o que o torna um ser consciente. E essa consciência do mundo ao redor se expressa no pensamento, sendo sua forma mais elevada o conceito.

\section{O conceito como concreto pensado}

Os conceitos são generalizações, abstrações da realidade objetiva no pensamento. Dessa forma, queremos deixar claro, em primeiro lugar, que as abstrações são históricas, ou seja, são determinadas pelas condições históricas e possuem validade para e nos limites delas (Marx, 2008). As abstrações dependem, portanto, das relações sociais em que se encontram e estas estão intimamente ligadas às forças produtivas. Ao desenvolver as forças produtivas, o ser humano transforma como se produz a vida - o modo de produção - e isso, por fim, transforma as próprias relações sociais, aquelas que organizam como se produz a vida em determinado momento histórico. E, da mesma forma que essas relações sociais são estabelecidas por seres humanos de acordo com sua produtividade material, também são estabelecidas as ideias, os princípios, as categorias para se pensar esse mundo de acordo com essas relações. “Assim, essas ideias, essas categorias são tão pouco eternas quanto as relações que exprimem. Elas são produtos históricos e transitórios" (Marx, 2009, p. 126, grifos no original). Podemos, assim, considerar os conceitos como impressões, reflexos momentâneos da realidade no pensamento, realidade esta que está em movimento, o que faz com que os conceitos também estejam em movimento (o que não quer dizer que estejam mudando a todo momento).

Donnangelo (2014, p. 73-74) exemplifica isso no caso do objeto saúde:

Então, na história do conceito saúde/doença, não disse que os conceitos saúde/ doença que estão aí, são ahistóricos e nunca poderão ser outros. O que eu disse é que eles não são outros. Eles estão aí, são históricos, foram montados daquele 
jeito e tinham que ser montados nos respectivos momentos de montagem, vamos dizer. Então, eu não posso dar uma penada neles por que (sic) eu não gosto deles. E achar que, só porque eu não gosto deles, há conceitos alternativos disponíveis. E esses conceitos terão que passar pelo mesmo processo de construção histórica dos demais.

Esse mundo ao redor, essa realidade objetiva é, portanto, apreendida pela consciência do ser humano, de forma histórica, dependendo das relações sociais em que se encontra e do desenvolvimento das forças produtivas alcançado até aquele momento. Essa apreensão da realidade pela consciência se realiza através de conceitos e abstrações, que são o "método que decompõe o todo para poder reproduzir espiritualmente a estrutura da coisa, e, portanto, compreender a coisa" (Kosik, 2011, p. 18).

Como vimos com a história dos Tropi, abstrair não é simplesmente ver o que existe de comum entre cada caso concreto - ou reunir as diferentes características existentes nos diferentes casos concretos de um mesmo fenômeno. Isso ainda é permanecer no concreto sensorial (fenomênico, da aparência), mas agora em múltiplos casos. Para realizar abstrações é preciso um esforço reflexivo de análise, o que permite que cheguemos nas abstrações mais gerais, que são aquelas que nos permitem entender como e porque surgiram esses casos concretos particulares; e com base nesse conhecimento, nos permite agir sobre eles de forma aprofundada. Dessa forma, abstrair significa analisar o objeto em estudo prescindindo das influências externas particulares (casuais) que não dizem respeito a sua essência e, depois disso, realizar generalizações, ou seja, baseado na essência do objeto, entendê-lo para todos os casos particulares, independentemente das diferentes aparências possíveis, e que esse entendimento seja específico, que não se aplique a outros casos que não daquela classe ou grupo de objetos. Assim, pode-se considerar o universal como um caso único (a essência), enquanto o particular como milhões de casos (as diversas especificidades dos diversos casos concretos - a realidade enquanto síntese de muitas determinações).

Partimos de nossos sentidos para entender essa realidade, entretanto, devemos ir além desse contato imediato com a aparência, buscando compreender também sua essência. Sempre que nos aproximamos de um objeto com o intuito de entendê-lo, começamos pelo contato entre nossos sentidos e as características dele (e fica claro que, com o desenvolvimento do conhecimento sobre o mundo, é possível estuda-los prescindindo deste 'toque' inicial, já realizado por outra pessoa em outro momento) e com isso começamos a conhecê-lo. Contudo, se pararmos nesse momento, esse conhecimento pode ser enganador, superficial. Por um lado, o objeto dificilmente se apresenta integralmente aos nossos sentidos e, por outro lado, nossos sentidos muitas vezes não conseguem captar todas as características 
do objeto. Nossos sentidos, ao tocar um pedaço de madeira, não nos dizem que ele é combustível que alimenta o fogo ou que ele pode ser transformado em diversas outras coisas (e, depois desse conhecimento estar difundido, torna-se parte fenomênica do objeto, presente no senso comum); aparentemente uma planta pode ser igual a todas as outras, porém ela é venenosa para o ser humano, entre outros exemplos. De acordo com Kosik (2011, p. 14, grifos no original), a forma fenomênica de um objeto e sua existência real além de diferentes, muitas vezes são “absolutamente contraditórias com a lei do fenômeno, com a estrutura da coisa e, portanto, com o seu núcleo interno essencial e o seu conceito correspondente".

Segundo Marx (2008), o concreto é concreto, porque ele é a síntese de muitas determinações, é a unidade do diverso, contendo em si mesmo o seu contrário. Ou seja, a realidade está repleta de contradições e o pensamento, auxiliado pelos conceitos, tem a possibilidade de compreender essa realidade contraditória. Dessa forma, o concreto é, ao mesmo tempo, ponto de partida e resultado da análise, pois é com base nele, da intuição e da representação, que se realizam abstrações para entendê-lo; mas ele é o resultado, porque aparece no pensamento como o processo da síntese. Ascender do abstrato ao concreto é o método, portanto, que permite ao pensamento se apropriar do concreto, reproduzi-lo mentalmente enquanto coisa concreta. Essa síntese, porém, "não é, de nenhum modo, o processo da gênese do próprio concreto" (Marx, 2008, p. 259), pois o pensamento não cria a realidade, mas é um instrumento que permite ao ser humano transformar a natureza para suprir suas necessidades - uma natureza que existe fora e independentemente do próprio pensamento. $\mathrm{O}$ todo que aparece no cérebro é um produto do cérebro pensante; entretanto, o objeto concreto permanece em pé antes e depois desse processo, independentemente dele; portanto, “o cérebro não se comporta senão especulativamente, teoricamente" (Marx, 2008, p. 260).

Depois de realizadas as abstrações, volta-se novamente ao concreto, mas agora o concreto que se vê não é mais aquele todo caótico da intuição, é agora um todo ordenado em que se entendem os fundamentos dos elos que ligam os diversos fenômenos e as múltiplas determinações do objeto; é o concreto pensado. É o fenômeno em suas íntimas leis, em sua essência, e não apenas em sua aparência. Segundo Kosik (2011), o todo - ou a totalidade - é a realidade ordenada, é um todo estruturado, dialético, no qual ou do qual um fato qualquer (classes de fatos, conjuntos de fatos) pode vir a ser racionalmente compreendido; isso não significa que a totalidade seja a soma de todos os fatos, ou o conhecimento de todos os fatos (como compreendem os positivistas), mas que cada fato seja tomado dentro da sua totalidade, mediante as relações constitutivas daquele fenômeno. Com base nesse fundamento, é possível compreender o fenômeno em sua concreticidade, como realidade concreta, síntese de múltiplas determinações. 
O método de análise que descrevemos, portanto, consiste em partir do concreto, do fenômeno, do particular, para se chegar às categorias mais universais, mais gerais e, apoiado nelas, entender as determinações que levam o fenômeno a fazer parte daquele todo; esse concreto é o ponto de chegada e também é o ponto de partida. Entretanto, é um novo ponto de chegada, pois agora está em um nível superior, não sendo mais um todo caótico, um concreto caótico, como no início da análise; e como esse concreto é síntese do diverso, toda nova determinação descoberta exige que esse trajeto seja feito novamente: parte-se novamente do ponto de partida para se voltar a ele como ponto de chegada, em cada iteração com novas determinações compreendidas. A cada novo trajeto (prática - teoria - prática), chega-se no fenômeno, no particular, com um reflexo cada vez mais rico, mais complexo, com um entendimento maior das determinações e das mediações existentes. Isso é necessário, pois a realidade é movimento, não é imóvel, estática, e é, principalmente, histórica. Deve-se continuamente realizar a ascensão do abstrato ao concreto, e verificar se o que no início da análise era verdade, ainda continua sendo, se o concreto pensado ainda continua correspondendo à realidade objetiva - o ponto de partida da análise.

Segundo Ilyenkov (2008, p. 137-138, tradução nossa):

Em outras palavras, pode-se dizer que a ascensão do concreto ao abstrato e a ascensão do abstrato ao concreto são duas formas mutuamente supostas de assimilação teórica do mundo, do pensamento abstrato. Cada um deles é realizado somente através de seu oposto e em unidade com ele. A ascensão do abstrato ao concreto sem seu oposto, sem a ascensão do concreto ao abstrato, tornaria-se uma ligação puramente escolástica das abstrações escassas prontas, emprestadas acriticamente. Ao contrário, uma redução do concreto ao abstrato, desempenhada aleatoriamente, sem uma ideia geral claramente percebida da pesquisa, sem uma hipótese, não pode e também não irá produzir uma teoria. Produzirá somente uma pilha disjunta de abstrações escassas.

A ascensão do abstrato ao concreto se conforma como um método que possibilita ao pensamento humano assimilar a realidade, que existe fora e independentemente dele. Esse método assume a existência de uma realidade não interpretada; além de uma atividade objetiva prática do ser humano social se desenvolvendo independente do pensamento; e de uma forma sensorial imediata de reflexo dessa realidade concreta objetiva na consciência. Isso significa que o pensamento teórico é posterior à existência do mundo objetivo. Esse é “o único método pelo qual o pensamento pode reproduzir no conceito, no movimento dos conceitos, a concreticidade historicamente estabelecida existindo fora e independentemente dele, um mundo existindo 
e se desenvolvendo fora e independentemente do pensamento" (Ilyenkov, 2008, p. 158, tradução nossa).

Ainda de acordo com Ilyenkov (2008, p. 165, tradução nossa):

O método da ascensão do abstrato ao concreto é primeiro de tudo um método de análise dos fatos empíricos reais. Enquanto tal, organicamente inclui em si mesmo o movimento reverso como seu contrário internamente necessário: cada passo neste caminho é exatamente um ato da ascensão da concreticidade dada sensorialmente a uma expressão teórica abstrata. É por isso que a ascensão do abstrato ao concreto no pensamento é ao mesmo tempo um movimento continuamente renovado do concreto em contemplação e noção ao concreto no conceito.

O método da ascensão do abstrato ao concreto nos permite refletir a realidade objetiva no pensamento, pois "no pensamento, o homem reflete a realidade de modo generalizado" (Vigotski, 2009, p. 12), por meio de conceitos, porque sem generalização o ser humano não seria capaz de pensar arbitrariamente, não conseguiria se desvencilhar do próprio objeto da ação; estaria sempre preso ao caso particular imediato. Segundo Lukács (2013, p. 65), “essa separação tornada consciente entre sujeito e objeto é um produto necessário do processo de trabalho e ao mesmo tempo a base para o modo de existência especificamente humano". E o ser humano consegue generalizar devido à linguagem, pois, por necessitar produzir sua vida em conjunto com outros seres humanos, necessita de comunicação, "estabelecida com base em compreensão racional e na intenção de transmitir ideias e vivências" no processo de trabalho (Vigotski, 2009, p. 11). Como o ser humano deixa de viver imediatamente com a natureza e passa a transformá-la através de mediações, os motivos de sua atividade podem não corresponder imediatamente ao seu objeto (torna-se uma ação), diferente dos outros animais, cujos motivos biológicos e o objeto nunca se separam (Leontyev, 2009).

É preciso, portanto, comunicar o que se pensa, pois a ação será realizada por diversos sujeitos, com diversos motivos, com um objetivo. A linguagem permite a criação de abstrações com significado que reflete o mundo objetivo, que por um lado, desenvolve o próprio pensamento devido às abstrações que ela criou e, por outro, permite exteriorizar o pensamento abstrato, generalizado, comunica ao outro sobre algo que não está presente imediatamente, ou sobre o passado e até mesmo um possível futuro (Lukács, 2013).

Nesse sentido, o espelhamento [da realidade no pensamento] tem uma natureza peculiar contraditória: por um lado, ele é o exato oposto de qualquer ser, precisamente porque ele é espelhamento, não é ser; por outro lado, e ao mesmo tempo, é o veículo através do qual surgem novas objetividades no ser social, para a reprodução deste no mesmo nível ou em um nível mais alto. Desse modo, a con- 
sciência que espelha a realidade adquire certo caráter de possibilidade (Lukács, 2013, p. 67).

No caso do capitalismo, segundo Leontyev (2009), no qual o trabalho é alienado, os motivos particulares dos sujeitos não estão articulados com os fins coletivos (ou seja, a satisfação de necessidades sociais); entretanto, mesmo que estes sujeitos não tenham consciência do objetivo final coletivo (apenas de seu objetivo específico particular), a própria forma como está estruturada a produção nessa sociedade torna possível que os objetivos particulares de cada sujeito particular atinjam o objetivo final, que é a produção de mercadorias. E a essa estrutura da produção soma-se a ideologia (como forma específica de consciência social) da classe dominante, com seus valores e diretrizes práticas, que se mostra mistificada como valores e diretrizes de todas as classes. Segundo Mészáros (2009, p. 35), isso permite que ocorra uma "falsa universalização da mais crua parcialidade".

E a unidade que permite analisar a linguagem e o psiquismo é a palavra (Vigotski, 2009). Segundo Luria (2001) e Vigotski (2009), a palavra não serve apenas para designar uma coisa e separar suas características ou designar um objeto isolado; ela serve para generalizar uma coisa, incluí-la em uma determinada categoria, referir-se a todo um grupo ou classe de objetos. Ao realizar a generalização dos objetos, a palavra se converte em um instrumento de abstração, a operação mais importante da consciência. Por isso, cada palavra é uma generalização latente, ela generaliza e, em termos psicológicos, é antes de tudo uma abstração. Além disso, ser um significado implica determinadas relações de generalidade com outros significados, se constituindo como uma medida específica de generalidade. Em outros termos, a palavra não é apenas um meio de substituição das coisas, mas a própria célula do pensamento, na medida em que a abstração e generalização são as funções mais importantes do pensamento. Além disso, a palavra é importante, pois é segundo ela que se forma o conceito e, posteriormente, ela torna-se seu símbolo.

Segundo Vigotski (2009, p. 170):

O conceito é impossível sem palavras, o pensamento em conceitos é impossível fora do pensamento verbal; em todo esse processo, o momento central, que tem todos os fundamentos para ser considerado causa decorrente do amadurecimento de conceitos, é o emprego específico da palavra, o emprego funcional do signo como meio de formação de conceitos.

Dessa forma, apreendemos a realidade objetiva por meio de conceitos, por meio de abstrações, já que em nossa análise "não podemos nos servir de microscópio nem de reagentes químicos" (Marx, 2013, p. 78). O conceito é engendrado após se abstraírem todas as características concreto-fatuais (as 
características casuais), permitindo chegar na essência do objeto (a célula mais geral), para, com base nessa essência, entender todos os casos particulares, independentemente das diferentes aparências que possam ter. Isso permite ao sujeito, apoiado nesse fundamento, compreender o fenômeno em sua concreticidade, como realidade concreta, síntese de múltiplas determinações (Marx, 2008). Ou seja, o conceito deve ser entendido como um método usado para decompor um objeto (um caso concreto, particular) em sua totalidade (em unidade), para reproduzir no pensamento a estrutura desse objeto e, dessa forma, compreender a sua estrutura. Para isso é mister abstrair os casos concretos ou as características concretas, partindo do concreto rumo ao abstrato (para depois realizar o segundo caminho, a ascensão do abstrato ao concreto), retirar os elementos que fazem com que ele possua concreticidade, e chegue em sua essência, sua qualidade de abstrato, à célula que explica o objeto, que não corresponde a qualquer caso concreto em particular, para entender o que os engendra. A abstração é, portanto, tanto o método quanto o resultado que se expressa na forma de conceito, ou seja, a abstração com significado.

A forma como se produz a vida em determinado momento histórico, um modo de produção estabelecido, engendra certa forma de explicar a própria realidade do ser humano, pois produz um certo conceito sobre o objeto estudado. E como o conceito é a reprodução mental da realidade objetiva, e esta é transformada pela humanidade enquanto totalidade, ele sempre é engendrado socialmente, não sendo algo criado aleatoriamente pelo indivíduo. Portanto, o conceito não é uma abstração vazia, e não é vazia exatamente por não conter concreticidade, por ser a essência 'social' do objeto estudado, objeto este que existe independentemente do pensamento humano.

Dessa forma, todo conceito é, por um lado, abstrato, pois contém em si apenas um momento particular da realidade concreta e não ela em sua totalidade. Por outro lado, todo conceito é concreto, pois, ao não englobar as características formais gerais dos fatos heterogêneos, ele explicita de forma mais precisa a definição do fato ao qual pertence e como este fato está relacionado ao todo agregado que é a realidade, desempenhando esta e não aquela função, possuindo este e não aquele significado. Portanto, todo conceito (e não as noções gerais) são 'abstrações concretas'; é sempre a coisa que é expressa nele, mas como uma coisa de acordo com a propriedade que possui especificamente como um elemento de um sistema concreto de coisas se relacionando entre si, e não como algo que pertence a uma esfera deslocada da realidade (Ilyenkov, 2008). “O abstrato não é, deste ponto de vista, somente um sinônimo do puramente ideal, existindo somente na consciência, no cérebro do homem na forma de sentido ou significado de uma palavra-signo" (Ilyenkov, 2008, p. 55, tradução nossa).

Assim, a todo conceito, mesmo àqueles mais abstratos, sempre corresponde um certo grau de realidade, que está representada no conceito de forma 
abstrata, segregada dessa mesma realidade. Até mesmo os conceitos que podemos considerar fictícios, matemáticos, são, em última análise, um reflexo das relações reais entre coisas e processos reais, mesmo que não resultem de um conhecimento experimental direto, mas tenham surgido com base no caminho dedutivo, mediante operações especulativas lógicas (Vigotski, 2004). Segundo Stewart (2013, p. 11): “O poder das equações reside na correspondência filosoficamente difícil entre a matemática, uma criação coletiva de mentes humanas, e uma realidade física externa".

Todo pensamento comporta uma abstração; e esta representa apenas uma das formas de sua conexão com o real e não um afastamento definitivo dela. Como é a prática social da própria humanidade o fundamento e o critério de validação do pensamento, essa distância aparente entre a teoria e a prática é o resultado da elevação do pensamento teórico para além das características sensoriais específicas que sustentam a atuação prática (Martins, 2013).

Só é possível existir o conceito de um fenômeno, em geral, se este é entendido não como um fenômeno recorrente, mas sim concretamente; isso significa considerar o papel e a posição do fenômeno em um sistema definido de fenômenos interagindo entre si, um sistema que forma certo todo coerente. O conceito existe em que o particular (os casos concretos) não é tomado como meramente o particular (apesar de recorrente), mas sim quando esses casos são tomados através de seus elos mútuos, através do universal, entendido como uma expressão do princípio que fundamenta estes elos. A formação de conceitos se dá com base na compreensão do fenômeno; e compreendê-lo significa estabelecer o lugar e o papel que ele desempenha no sistema concreto de fenômenos que estão interagindo entre si, no qual ele é necessariamente realizado; é encontrar aqueles traços que tornam possível que ele desempenhe aquele papel no todo. Compreender o fenômeno significa descobrir o modo de sua origem, descobrir a regra que faz com que ele se engendre necessariamente naquela totalidade concreta de condições, significa analisar as próprias condições da sua origem (Ilyenkov, 2008).

Por conseguinte, dominar um conceito não significa aprender seus aspectos formais e verbais, mas sim compreender a realidade que ele contém (Martins, 2013), pois o conhecimento sempre é conhecimento de um objeto e não de um sistema de frases sobre o objeto segundo uma conexão imaginária, tênue, entre ambos. Ou seja, não é um problema puramente linguístico, no qual se assimila a linguagem disponível e depois os fatos na forma dessa linguagem - como fazem os neopositivistas (Ilienkov, 2016a). Dessa forma, a realidade concreta é o conteúdo do conceito, conteúdo submetido à formulação de juízos lógicos que permite que a realidade objetiva seja refletida no 
pensamento através das conexões entre objetos e fenômenos (Martins, 2013). Definir um conceito, portanto, não significa descobrir qual o sentido que foi atribuído ao termo pelas pessoas. "Definir um conceito significa definir o objeto. A partir da perspectiva do materialismo, é uma e a mesma coisa. A única definição correta é, portanto, chegar à essência da questão" (Ilyenkov, 2008, p. 52, tradução nossa).

\section{A possibilidade de um conceito de saúde}

Consideramos que os conceitos são a forma superior de pensamento, pois se constituem como uma grande elaboração reflexiva como forma de reproduzir mentalmente o concreto da realidade objetiva. E como o conceito sempre é engendrado socialmente, ele parte de como se produz a vida em determinado lugar e em determinado momento histórico, ou seja, ele não é criado aleatoriamente pelo indivíduo. Salientamos, assim, que essa construção, sendo sempre histórica, é igualmente delimitada por essa sua historicidade, o que quer dizer que os conceitos sempre serão historicamente reelaborados. Como disse Lefebvre (1983, p. 98, grifos no original): “O relativismo dialético admite a relatividade de nossos conhecimentos, não no sentido de uma negação da verdade objetiva, mas no sentido de uma perpétua superação dos limites de nosso conhecimento".

O conceito é sempre a realidade objetiva, com suas múltiplas determinações, reproduzida no pensamento, pois abstrair as características concretofatuais (casuais) dos objetos é o que permite se entender a relação dessas características com o todo em que o objeto está inserido. Portanto, é possível reproduzir mentalmente todo e qualquer objeto sem prescindir de suas contradições, complexidade e diversidade. O mesmo ocorre com a complexidade da vida humana, que, dessa forma, pode ser reproduzida mentalmente na forma de conceito.

Sendo a saúde parte dessa vida, ou seja, constituindo-se como coisa real, objetiva, apesar de toda sua complexidade e diversidade (que não são exclusividade sua) e de aparecer de forma diferente em cada caso concreto (para cada pessoa), ela pode ser conceituada e não só nomeada, pois, como essência, universalidade, é exatamente aquilo que explica cada caso particular, a própria complexidade de cada caso concreto. Lembremos, contudo, que conceituá-la, em nossos referenciais, significa sempre a busca das conexões entre o concretofatual e o todo social em que se insere, para cada tempo histórico considerado. Na ausência de tal reconstrução reflexiva, poderemos apenas descrever o que ocorre na realidade empírica, sem buscar a compreensão dessa ocorrência em termos do seu significado social. E considerando que, na área da saúde, a forte presença dos referenciais biomédicos tende a reduzir toda prática de 
saúde à sua dimensão técnica, como se fosse possível com isso isentá-la de compromissos para com o social, é particularmente importante no conceito refazer os laços entre a técnica e o social, com o que damos sentido político à própria técnica (Donnangelo, 2014).

\section{Considerações finais}

Buscamos, com o presente estudo, argumentar que é possível existir um conceito de saúde. De forma subsequente, o caminho para a análise do conceito de saúde precisa, portanto, partir das condições concretas de existência do ser humano que, hoje em dia, se conformam dentro de uma forma social chamada capitalismo e que possui suas particularidades que a diferenciam de outras formas sociais. Desse concreto, precisaremos realizar abstrações para poder apreender a saúde no pensamento e com base na essência encontrada, poder entender as relações existentes, nos casos particulares, entre suas particularidades e o social.

\section{ACERCA DE LAS POSIBILIDADES DE UN CONCEPTO DE SALUD}

Resumen El estudio tiene como objetivo discutir lo que es un concepto a partir de la adopción de las referencias teóricas marxistas para definirlo, con la intención de responder si es posible que exista un concepto de salud o no. Se realizó una lectura de autores marxistas que tratan sobre la relación entre el pensamiento y la realidad objetiva, buscando apoyarse en diversos autores dentro de este marco referencial, para enriquecer el debate contemporáneo en la Salud Pública. Como resultado, entendemos que el concepto es la forma de percepción a través del pensamiento de los objetos presentes en la realidad objetiva y que, exactamente por no incluir las características concretas-fácticas presentes en cada caso particular, permite comprenderlos con base en su esencia como objeto abstracto-universal. De esta forma, concluimos que, a pesar de la salud ser un objeto extremadamente complejo, es posible que exista su concepto, el cual, de acuerdo con nuestras referencias, debe hacer referencia al conjunto sociohistórico en su total y a la politización de la dimensión técnica que esté implicada históricamente con este aspecto social.

Palabras clave salud pública; formación de concepto; salud; trabajo; conocimiento. 


\section{Referências}

BLUNDEN, Andy. An interdisciplinary theory of activity: studies in critical social science. Chicago: Haymarket Books, 2012.

BORUCHOVITCH, Evely; MEDNICK, Birgitte R. The meaning of health and illness: some considerations for health psychology. PsicoUSF, Campinas, v. 7, n. 2, p. 175-183, 2002.

COSTA, Márcio L.; BERNARDES, Anita G. Produção de Saúde como afirmação de vida. Saúde e Sociedade, São Paulo, v. 21, n. 4, p. 822-835, 2012.

CZERESNIA, Dina. The concept of health and the difference between prevention and promotion. Caderno de Saúde Pública, Rio de Janeiro, v. 15, n. 4, p. 701-709, 1999.

CZERESNIA, Dina; MACIEL, Elvira M. G. S.; OVIEDO, Rafael A. M. Os sentidos da saúde $e$ da doença. Rio de Janeiro: Editora da Fiocruz, 2013.

DALMOLIN, Bárbara B. et al. Significados do conceito de saúde na perspectiva de docentes na área da saúde. Escola Anna Nery Revista de Enfermagem, Rio de Janeiro, v. 15, n. 2, p. 389-394, 2011.

DONNANGELO, Maria C. F. A conceptualização do social na interpretação da doença: balanço crítico. In: CARVALHEIRO José R., HEIMANN, Luiza S.; DERBLI, Márcio. (Org.). O social na epidemiologia: um legado de Cecília Donnangelo. São Paulo: Instituto de Saúde, 2014. p. 47-84.

DUARTE, Newton. Sociedade do conhecimento ou sociedade das ilusões?. Campinas: Autores Associados, 2008.

KOSIK, Karel. A dialética do concreto. 2.ed. 9. reimpr. Rio de Janeiro: Paz e Terra, 2011.

ILIENKOV, Evald V. Atividade e conhecimento. In: SILVA, Marcelo J. S. (Org.). A dialética do ideal: escritos de E. V. Ilienkov. Curitiba: Ed. UFPR, 2016a. p. 39-50.
ILIENKOV, Evald V. O universal. In: SILVA, Marcelo J. S. (Org.). A dialética do ideal: escritos de E. V. Ilienkov. Curitiba: Ed. UFPR, 2016b. p. 75-106.

ILYENKOV, Evald V. The dialectics of the abstract and the concrete in Marx's Capital. Delhi: Aakar Books, 2008.

LEFEBVRE, Henri. Lógica formal / Lógica dialética. 3.ed. Rio de Janeiro: Civilização Brasileira, 1983.

LEONTYEV, Aleksei N. The development of mind. Pacifica: Marxists Internet Archive, 2009.

LUKÁCS, György. Para uma ontologia do ser social. São Paulo: Boitempo, 2012.

LUKÁCS, György. Para uma ontologia do ser social II. São Paulo: Boitempo, 2013.

LURIA, Aleksandr R. Pensamento e linguagem: as últimas conferências de Luria. Porto Alegre: Artes Médicas, 2001.

MAHER, Stephen. Escaping structuralism's legacy: the renewal of theory and history in historical materialism. Science \& Society, New York, v. 80, n. 3, p. 291-318, 2016.

MAMARDAŠVILI, Merab. Analysis of consciousness in the works of Marx. Studies in Soviet Thought, New York, v. 32, n. 2, p. 101-120, 1986.

MARTINS, Ligia M. O desenvolvimento do psiquismo e a educação escolar: contribuições à luz da psicologia histórico-cultural e da pedagogia histórico-crítica. Campinas: Autores Associados, 2013.

MARX, Karl. Contribuição à crítica da economia política. 2.ed. São Paulo: Expressão Popular, 2008.

MARX, Karl. Miséria da filosofia: resposta à Filosofia da miséria, do sr. Proudhon. São Paulo: Expressão Popular, 2009. 
MARX, Karl. O capital: crítica da economia política. Livro I: o processo de produção do capital. São Paulo: Boitempo, 2013.

MARX, Karl; ENGELS, Friedrich. A ideologia alemã: crítica da mais recente filosofia alemã em seus representantes Feuerbach, B. Bauer e Stirner, e do socialismo alemão em seus diferentes profetas (1845-1846). São Paulo: Boitempo, 2009.

MÉSZÁROS, István. A teoria da alienação em Marx. São Paulo: Boitempo, 2009.

SILVA, Marcelo J. S. Evald Vasilievich Ilienkov: um marxista a ser descoberto. Marx e o Marxismo, Niterói, v. 4, n. 6, p. 95-110, 2016.

SILVA, Marcelo J. S. O conceito de saúde na Saúde Coletiva: contribuições a partir da crí- tica social e histórica à tomada do corpo e seu adoecimento na medicina da modernidade. 2017. 110f. Tese (Doutorado em Medicina Preventiva)-Faculdade de Medicina, São Paulo, USP, 2017.

STEWART, Ian. Dezessete equações que mudaram o mundo. Rio de Janeiro: Zahar, 2013.

VÁZQUEZ, Adolfo S. Filosofia da práxis. 2.ed. Buenos Aires: Consejo Latinoamericano de Ciencias Sociales; São Paulo: Expressão Popular, 2011.

VIGOTSKI, Lev S. Teoria e método em psicologia. 3.ed. São Paulo: Martins Fontes, 2004.

VIGOTSKI, Lev S. A construção do pensamento e da linguagem. 2.ed. São Paulo: WMF Martins Fontes, 2009.

\section{Errata}

No ensaio DAS POSSIBILIDADES DE UM CONCEITO DE SAÚDE, com número de DOI: 10.1590/1981-7746-sol00193, publicado no periódico Trabalho, Educação e Saúde, v. 17, n. 1, identificador eletrônico 17(1):e0019320, página 1, foi incluído o seguinte nome do autor com seu respectivo número de ORCID:

André Mota² (0000-0002-5697-8628) 